\title{
Challenges to Quality Primary Health Care in Saudi Arabia and Potential Improvements Implemented by Other Systems: Systematic Review
}

\author{
Abdullah Ghthaith Almutairi ${ }^{1} \&$ Hilal Salim Al Shamsi ${ }^{2}$ \\ ${ }^{1}$ Director of Tumair Hospital, Ministry of Health, AL Riyadh, Saudi Arabia \\ ${ }^{2}$ Director of Planning \& Studies, Directorate General of Planning and Studies, Al-Buraimi Governorate, Ministry of \\ Health, Oman \\ Correspondence: Hilal Salim Al Shamsi, Director of Planning and Studies, Directorate General of Health Services, \\ Al-Buraimi Governorate, Ministry of Health, Oman. E-mail: alshamsi28@yahoo.com
}

Received: January 19, 2020 Accepted: June 10, 2020 Online Published: June 25, 2020

doi:10.5539/gjhs.v12n9p1 URL: https://doi.org/10.5539/gjhs.v12n9p1

\begin{abstract}
Introduction: As primary healthcare centres play an important role in implementing Saudi Arabia's health strategy, this paper offers a review of publications on the quality of the country's primary health care. With the aim of deciding on solutions for improvement, it provides an overview of healthcare quality in this context and indicates barriers to quality.

Method: Using two databases, ProQuest and Scopus, data extracted from published articles were systematically analysed for determining the care quality in Saudi primary health centres and obstacles to achieving higher quality.

Results: Twenty-six articles met the criteria for inclusion in this review. The components of healthcare quality were examined in terms of the access to and effectiveness of interpersonal and clinical care. Good access and effective care were identified in such areas as maternal health care and the control of epidemic diseases, whereas poor access and effectiveness of care were shown for chronic disease management programmes, referral patterns (in terms of referral letters and feedback reports), health education and interpersonal care (in terms of language barriers). Several factors were identified as barriers to high-quality care. These included problems with evidence-based practice implementation, professional development, the use of referrals to secondary care and organisational culture. Successful improvements have been implemented by other systems, such as mobile medical units, electronic referrals, online translation tools and mobile devices and their applications; these can be implemented in Saudi Arabia for improving the quality of the primary healthcare system in this country.
\end{abstract}

Conclusion: The quality of primary health care in Saudi Arabia varies among the different services. To improve quality, management programmes and organisational culture must be promoted in primary health care. Professional development strategies are also needed for improving the skills and knowledge of healthcare professionals. Potential improvements can be implemented to improve the quality of the primary health system.

Keywords: quality, primary health care, Saudi Arabia, health centres, general medical, family practice, community medicine

\section{Introduction}

Primary health care is the first point of healthcare provision for most people. The World Health Organization [WHO] (2008) reported that the value of primary health care is achieving health throughout the healthcare system by bringing people into the primary care centres. Since the Alma Ata Declaration in 1978, Saudi Arabia has treated the development of key primary healthcare features as one of the country's most important strategies (Littlewood \& Yousuf, 2000). In 2013, the Ministry of Health had 2259 primary health centres throughout the country, with a ratio of 7.53 per 100,000 members of the population (Ministry of Health- Saudi Arabia, 2013).

The quality of health care varies in the United States and other countries around the world (Schuster, McGlynn, \& Brook, 2005), and like other countries, Saudi Arabia faces several challenges. These include a shortage of Saudi health professionals, high demand for services, rising costs, poor accessibility to some healthcare facilities and changing 
patterns of disease (Al-Mutairi, 2017).

Healthcare quality has been defined as a multidimensional concept (Duggirala, Rajendran, \& Anantharaman, 2008; Raposo, Alves, \& Duarte, 2009). The dimensions of a quality health system have been identified as accessibility, effectiveness, efficiency, equitability and safety (WHO, 2006). Indeed, quality has long been promoted as an integral part of primary health care in Saudi Arabia. In 1993, the country's national guidelines for quality control in primary health care were established, covering the main features of primary health care, including chronic disease management, health education, the management of communicable diseases and environmental health, community participation, prescriptions, referrals, immunisation, paediatric health care and maternal health care (Al-Ahmadi \& Roland, 2005). Moreover, in 1995, a management development and personnel programme was initiated in the country's primary healthcare institutions (Almasabi, 2013). In this programme, managers were trained to improve their levels of efficiency and help in the quality improvement efforts being implemented in primary healthcare centres (Al-Ahmadi \& Roland, 2005; Almasabi, 2013). However, more than 20 years after the implementation of Saudi Arabia's primary healthcare and quality control programmes, little information about primary healthcare quality is available. This review gives an overview of the Saudi primary healthcare quality and determines obstacles to quality in the country's primary healthcare institutions.

\section{Methodology}

\subsection{Searches and Data Sources}

A comprehensive search was performed to obtain studies on the quality of primary health care in Saudi Arabia. The databases used in the search included ProQuest and Scopus, and the keywords used were 'quality', 'primary health care', 'Saudi Arabia', 'health centres', 'general medical', 'family practice' and 'community medicine'. These keywords were used to find articles with matching terms in their abstracts or titles. To discover the most recent studies and literature on our review topic, the search was limited to articles published between 2000 and 2018.

\subsection{Inclusion and Exclusion Criteria}

This review included studies that reported on the quality of primary health care in Saudi Arabia and were published in English between 2000 and 2018. Studies with small sample sizes $(n<100)$ and response rates $(<60 \%)$ were excluded, as were non-peer-reviewed articles. Exclusion was also applied to articles related to primary health care but not quality.

\subsection{Data Extraction}

The extracted data are summarised in two tables. Table 1 includes the general characteristics of the literature and studies reviewed, specifically, the type of study, data collection method, sample size, response rate, region and type of organisation where the study was performed. Table 2 focusses on the results of the primary healthcare quality reviews and barriers to quality in each study and lists which dimension of healthcare quality each article addressed.

\section{Results}

Figure 1 presents the method used for selecting eligible studies for this review. In the first stage, ProQuest and Scopus returned 3288 articles. After duplicate articles and those published before 2000 were removed, 624 remained. Non-peer-reviewed articles (275) and articles not mainly about quality in primary health care (221) were then excluded. After excluding studies with sample sizes under 100 and response rates under 60\%, 26 articles were included in this review. 


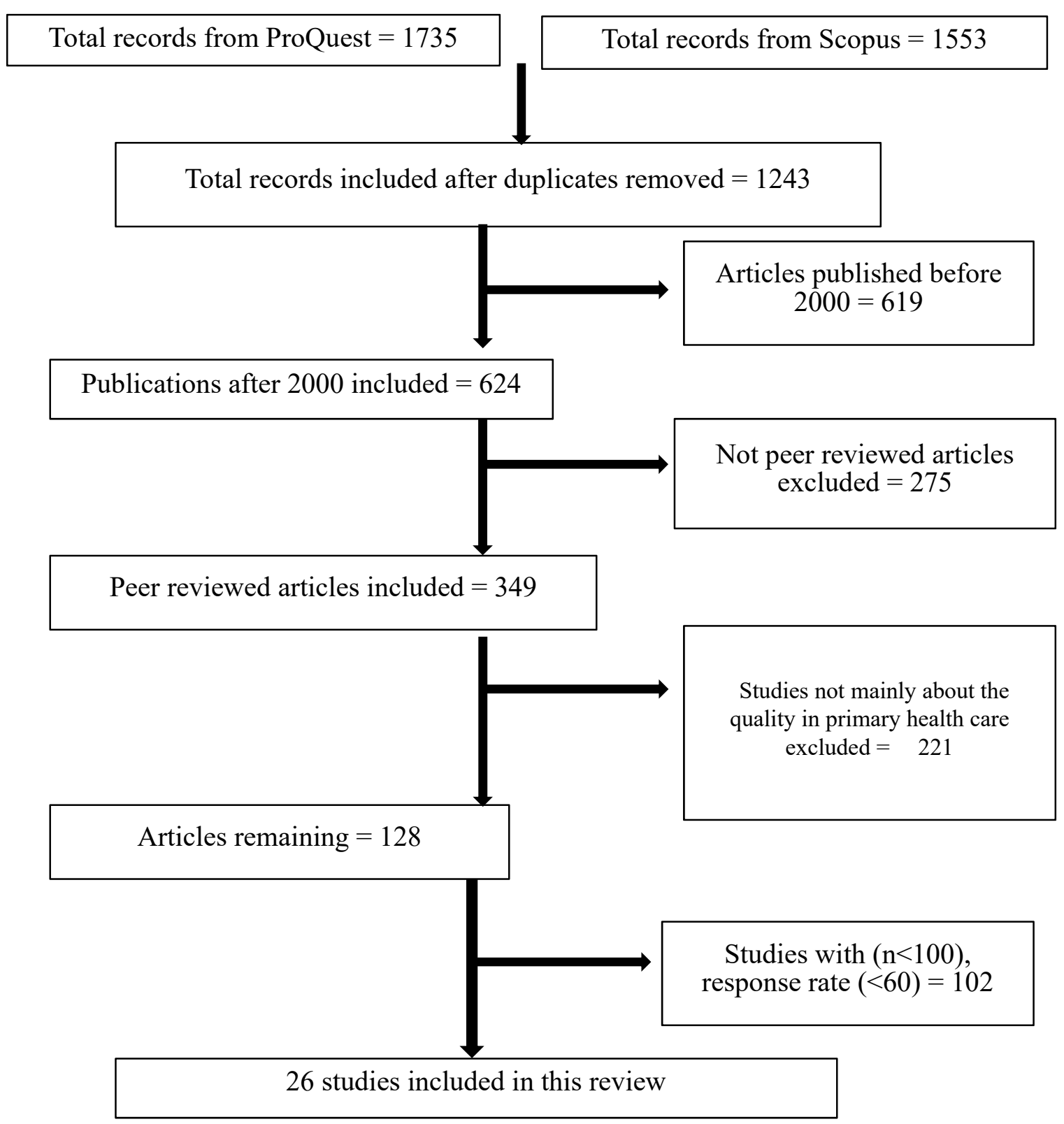

Figure 1. The process of selecting the 26 articles, which are contained in this review

Tables 1 and 2 show summaries of the general characteristics and most important findings of the 26 studies. Among the studies, five were from southern, seven from eastern, eight from central and two from northern and western Saudi Arabia, while three were from Mexico, Canada and Germany. The remaining article incorporated multiple countries, specifically, the United Kingdom, Norway, Finland, Netherlands, Denmark, New Zealand, Canada, Australia and the United States. Most of the studies were carried out in the primary health institutions of the Ministry of Health, while two were carried out in an army health institution. Fifteen studies collected data by questionnaire, seven through medical records and four by interview. The total sample size of all the studies was 9997, while the individual studies' sample sizes ranged from 39 to 1553 , with response rates ranging from $61 \%$ to $100 \%$.

Most of the studies included in this review focussed on administration, clinical care and interpersonal care (Table 2). The results of these studies can be divided into two main categories: the quality of care provided and obstacles to providing quality care. 


\subsection{Quality of Care Provided}

Access

Maternal care was reported to be available in both urban (67\%) and rural (96\%) areas (El-Gilany \& Aref, 2000). The distances between PHCCs and patients' homes were reported to be acceptable and to provide easy access to centres $(86 \%)$. Access to the chronic diseases programme was observed to be below target (Al-Jaber \& Da'ar, 2016; Al-Khaldi \& Khan, 2000; Al-Mustafa \& Abulrahi, 2003). For instance, only a small number of registered hypertension patients had visited centres for treatment (16-36\%; (Al-Mustafa \& Abulrahi, 2003). Dental services were observed to be unavailable in primary health centres $(28 \%)$, and the cost of private dental services was reported to be high $(37 \%$; (Al-Jaber \& Da'ar, 2016). Low referral rates and missed appointments reportedly prevented appropriate access to specialist care to health services; most primary care institutions had established registers, appointment systems and follow-up systems (Alhamad, 2013; Kishk \& Al Juhani, 2006). Finally, the mobile unit had reduced 35\% of attendance for outpatient clinics, which can be a solution to providing health services without needing to provide clinics (Diaz-Perez, Farley, \& Cabanis, 2004).

\section{Effectiveness}

Many studies have indicated that several primary healthcare programmes have been effective, including diabetes care education (Al-Khaldi \& Khan, 2000) and maternal health care (El-Gilany \& Aref, 2000). As a result of the diabetes health education programme, about $73 \%$ of diabetic patients received health education on relevant topics, which helped physicians communicate more effectively with them (Al-Khaldi \& Khan, 2000). The expanded maternal services programme increased maternal care coverage to $96 \%$ in rural areas and $67 \%$ in urban areas (El-Gilany \& Aref, 2000). In contrast, resources for primary diabetic care were inadequate (Al-Khaldi \& Al-Sharif, 2002). Many factors contributed to this, including a lack of access to essential drugs $(10-18 \%)$, lack of coordination with secondary providers regarding diabetic care (65\%), lack of appointment systems for diabetic care $(10 \%)$ and lack of training in diabetic care nurses $(57 \%)$ and doctors $(80 \%)$.

Nursing staff were also dissatisfied with working life in primary care, for reasons like inadequate salary $(61 \%)$, working environments that felt unsafe (60\%) and long working hours (71\%; (Almalki et al., 2012). A Canadian study from 2011 reported that $85 \%$ of the participants used mobile devices and their applications to access new information because such devices allow flexible, quick and easy access to multi-media, journals and medical news (Wallace et al., 2012).

\subsection{Obstacles to Providing Quality Care}

This review identified four factors that delay the achievement of quality primary health care in Saudi Arabia. These are difficulties in the implementation of evidence-based medicine (EBM), problems at the interface with secondary providers, issues with professional development strategies and organisational culture.

\section{Inadequate implementation of EBM}

National guidelines have been established for several common conditions; however, some studies have shown that clinical decisions are not adequately evidence based (Al-Ansary \& Khoja, 2002; Dashash \& Mukhtar, 2003; Khan et al., 2011). This has contributed to inadequate diagnoses, inappropriate clinical decisions, wide practice variations and unsafe prescription patterns (Al-Ansary \& Khoja, 2002; Dashash \& Mukhtar, 2003). The implementation of evidence-based medicine faces such obstacles as poor guideline dissemination 
Table 1. Summary of general characteristics of the included studies in this review

\begin{tabular}{|c|c|c|c|c|c|c|c|}
\hline Author & Region & $\begin{array}{l}\text { No. } \\
\text { Organization }\end{array}$ & $\begin{array}{l}\text { Type of } \\
\text { Organization }\end{array}$ & $\begin{array}{l}\text { Study } \\
\text { type }\end{array}$ & $\begin{array}{l}\text { Data } \\
\text { Collection }\end{array}$ & Sample size & $\begin{array}{l}\% \text { of } \\
\text { response }\end{array}$ \\
\hline (Al-Ahmadi \& Roland, 2005) & South & One family practice & Health Authority & Cross-sectional & Medical records & 864 & NR \\
\hline $\begin{array}{l}\text { (Al-Alfi, Al-Saigul, Abed-Elbast, } \\
\text { Sourour, \& Ramzy, 2007) }\end{array}$ & Central & 6 PHCs & $\mathrm{MOH}$ & Retrospective & Medical Records & 330 & NA \\
\hline (Al-Ansary \& Khoja, 2002) & Central & 275 PHCCs & $\mathrm{MOH}$ & Cross-sectional & Questionnaire & 650 & 89 \\
\hline (Albattal, 2014) & Central & One health center & Military & Cross-sectional & Questionnaire & 101 & 80 \\
\hline $\begin{array}{l}\text { (Albrecht, Behrends, Schmeer, } \\
\text { Matthies, \& Von Jan, 2013) }\end{array}$ & Germany & Hospital & $\mathrm{MOH}$ & Cross-sectional & Questionnaire & 39 & 90 \\
\hline $\begin{array}{l}\text { (Alfaqeeh, Cook, Randhawa, \& } \\
\text { Ali, 2017) }\end{array}$ & Central & 10 PHCCS & $\mathrm{MOH}$ & Cross-sectional & Questionnaire & 1032 & 91 \\
\hline (Alhamad, 2013) & Central & One general clinic & Military & Case-control & Medical Records & 750 & 86 \\
\hline (Al-Jaber \& Da'ar, 2016) & Central & 2 PHCCs & $\mathrm{MOH}$ & Cross-sectional & Questionnaire & $\begin{array}{l}242 \text { health } \\
\text { centers }\end{array}$ & 95 \\
\hline (Al-Khaldi \& Al-Sharif, 2002) & Southwest & 242 health centers & $\mathrm{MOH}$ & $\begin{array}{l}\text { Retrospective } \\
\text { study }\end{array}$ & Questionnaire & $\begin{array}{l}242 \text { health } \\
\text { centers }\end{array}$ & 99 \\
\hline (Al-Khaldi \& Khan, 2000) & South & One health center & $\mathrm{MOH}$ & $\begin{array}{l}\text { Retrospective } \\
\text { study }\end{array}$ & $\begin{array}{l}\text { Medical records for } \\
\text { diabetic patients }\end{array}$ & 198 & NR \\
\hline $\begin{array}{l}\text { (Al-Khathami, Kojan, Aljumah, } \\
\text { Alqahtani, \& Alrwaili, 2010) }\end{array}$ & Central & NR & $\mathrm{MOH}$ & Cross-sectional & Questionnaire & 116 & 100 \\
\hline $\begin{array}{l}\text { (Al-Makhaita, Sabra, \& Hafez, } \\
\text { 2014) }\end{array}$ & East & 24 PHCCs & $\mathrm{MOH}$ & Cross-sectional & Questionnaire & 144 & 99 \\
\hline $\begin{array}{l}\text { (Almalki, FitzGerald, \& Clark, } \\
\text { 2012) }\end{array}$ & Southern & 134 PHCCs & $\mathrm{MOH}$ & Cross-sectional & Questionnaire & 582 & 92 \\
\hline $\begin{array}{l}\text { (Almoajel, Fetohi, \& Alshamrani, } \\
\text { 2014) }\end{array}$ & Eastern & NR & $\mathrm{MOH}$ & Cross-Sectional & Questionnaire & 200 & NR \\
\hline (Al-Mosilhi \& Kurashi, 2006) & East & 76 health centers & $\mathrm{MOH}$ & Cross-sectional & Questionnaire & 199 & 61 \\
\hline (Al-Mustafa \& Abulrahi, 2003) & East & 13 PHCCS & $\mathrm{MOH}$ & $\begin{array}{l}\text { Retrospective } \\
\text { cohort study }\end{array}$ & $\begin{array}{l}\text { Medical records of adult } \\
\text { hypertension patients }\end{array}$ & 320 & NR \\
\hline
\end{tabular}




\begin{tabular}{|c|c|c|c|c|c|c|c|}
\hline (Alsharif \& Al-Khaldi, 2001) & South & $\begin{array}{l}\text { All Aseer region } \\
\text { PHCCS }\end{array}$ & $\mathrm{MOH}$ & Cross-sectional & Questionnaire & 383 & 86 \\
\hline (Alzaied \& Alshammari, 2016) & Central & NR & $\mathrm{MOH}$ & Cross-sectional & Questionnaire & 426 & 91 \\
\hline (Bawakid et al., 2017) & East & NR & $\mathrm{MOH}$ & Cross-sectional & Interview & 246 & 92 \\
\hline (Dashash \& Mukhtar, 2003) & West & One health center & National Guard & $\begin{array}{l}\text { Retrospective } \\
\text { study }\end{array}$ & Medical records & 206 & NR \\
\hline (Diaz-Perez et al., 2004) & $\begin{array}{l}\text { Mexico- rural } \\
\text { Northern }\end{array}$ & $\begin{array}{l}\text { Community health } \\
\text { center }\end{array}$ & $\mathrm{MOH}$ & Cross-sectional & Medical records & 1553 & NR \\
\hline (El-Gilany \& Aref, 2000) & North & 6 PHCCs & $\mathrm{MOH}$ & $\begin{array}{l}\text { Retrospective } \\
\text { cohort study }\end{array}$ & Interview & 375 & NR \\
\hline $\begin{array}{l}\text { (Khan, Lateef, Khamseen, Al } \\
\text { Aithan, \& Al Ibrahim, 2011) }\end{array}$ & East & Health Directorate & $\mathrm{MOH}$ & Cross-sectional & Questionnaire & 122 & 82 \\
\hline (Kishk \& Al Juhani, 2006) & Eastern & 32 health centers & $\mathrm{MOH}$ & Cross-sectional & Questionnaire & 445 & 79 \\
\hline (Tian, 2011) & $\begin{array}{l}\text { UK, Norway, } \\
\text { Finland, } \\
\text { Netherlands, } \\
\text { Denmark, } \\
\text { Scotland, New } \\
\text { Zealand, } \\
\text { Canada, } \\
\text { Australia, and U. } \\
\text { S }\end{array}$ & NR & $\mathrm{MOH}$ & NA & Interview & NR & NR \\
\hline (Wallace, Clark, \& White, 2012) & Canada & Medical School & $\mathrm{MOH}$ & Cross-sectional & Interview & 232 & $100 \%$ \\
\hline
\end{tabular}

*MOH: The ministry of health, NR: Not recorded, NA: Not applicable. 
(Dashash \& Mukhtar, 2003); poor understanding of course technology terminology; a low level of awareness of review publications, journals and databases among physicians (Al-Ansary \& Khoja, 2002); and disagreements of physicians with disease self-management education (Khan et al., 2011). Most physicians have limited access to the internet (Al-Ansary \& Khoja, 2002).

Table 2. Important findings from this review

\begin{tabular}{llll}
\hline Author & Dimension & Focus & Results \\
\hline (Al-Ahmadi \& Roland, 2005) & $\begin{array}{l}\text { Interface with secondary } \\
\text { care }\end{array}$ & communication & $\begin{array}{l}\text { Hospital feedback was released only if it required by primary healthcare or patient, referral } \\
\text { letters were delivered by patients, feedback report lacked the information: } \\
\text { Diagnosis (15\%), advice (100\%), and result of investigation (21\%). }\end{array}$ \\
\hline (Al-Alfi et al., 2007) & $\begin{array}{l}\text { Interface with secondary } \\
\text { care }\end{array}$ & communication & $\begin{array}{l}\text { Lack of information in referral form: history (36\%), vital signs (30\%), result of examination } \\
(47 \%) .\end{array}$ \\
& & Feedback report received only 30\% of referral to hospital.
\end{tabular}

Feedback report received only $30 \%$ of referral to hospital.

Physicians had a high attitude towards evidence based medical.

Barriers the course:

(Al-Ansary \& Khoja, 2002) Evidence based medicine Attitude/ barrier

Lack of personal time (22\%), overload (29\%), limited to access to references $(16 \%)$ and internet $(10 \%)$.

Low level of awareness for:

Review publications and journals, and low understanding of the course technical terminology. Implementing referral system, reduce $32 \%$ of visits in hospital.

The main factors for inappropriate referrals, GP reported: poor awareness of the available clinics of secondary care $(67 \%)$, lack of referral feedback $(86 \%)$, difficult to communicate with specialists by phone (91\%). To improve referral process, should be periodic referral auditors (84\%).

MediBabble application had been implemented in health organisations to overcome language barriers.

(Albrecht et al., 2013) 


\begin{tabular}{|c|c|c|c|}
\hline (Alfaqeeh et al., 2017) & Access & Patient satisfaction & $\begin{array}{l}\text { Distance from patients' residence to health centers is problem, in (28\%) rural region, }(12 \%) \\
\text { urban region. }\end{array}$ \\
\hline \multirow{2}{*}{ (Alhamad, 2013) } & & & Missing an appointment was from $24 \%$ to $30 \%$. \\
\hline & Access / Effectiveness & Appointment & $\begin{array}{l}\text { Reasons for missing an appointment: difficult to book an appointment, long distance, } \\
\text { unavailability of transportation, and visiting another health center. }\end{array}$ \\
\hline \multirow[b]{2}{*}{ (Al-Jaber \& Da’ar, 2016) } & \multirow[b]{2}{*}{ Access/ effectives } & \multirow[b]{2}{*}{ Oral health care } & Challenges face by patients: - \\
\hline & & & $\begin{array}{l}\text { An unavailable dentist in PHCC }(28 \%) \text {, and that explains why }(77 \%) \text { of patients indicate private } \\
\text { dental clinics. }(37 \%) \text { the high cost of private dental clinics }\end{array}$ \\
\hline \multirow[b]{2}{*}{$\begin{array}{l}\text { (Al-Khaldi \& Al-Sharif, } \\
\text { 2002) }\end{array}$} & \multirow[b]{2}{*}{ Organization effectives } & \multirow[b]{2}{*}{$\begin{array}{l}\text { Resources of } \\
\text { diabetes care }\end{array}$} & Inadequate resource items for diabetic care: \\
\hline & & & $\begin{array}{l}\text { Only between } 10 \% \text { and } 18 \% \text { essential drugs, } 65 \% \text { of centers did not have coordination with } \\
\text { hospital about diabetic care, } 74 \% \text { have a mini diabetic clinic, } 10 \% \text { did not have an appointment } \\
\text { system for diabetic care, } 43 \% \text { had training nurse on health education, } 8 \% \text { health education, } 20 \% \\
\text { of doctors trained on diabetic care. }\end{array}$ \\
\hline (Al-Khaldi \& Khan, 2000) & Access/ effectives & $\begin{array}{l}\text { Health educations } \\
\text { diabetes }\end{array}$ & $\begin{array}{l}\text { Diabetic patients who received health education: } \\
(21 \%) \text { medication, }(80 \%) \text { diabetes, }(44 \%) \text { insulin injection, }(25 \%) \text { exercise, }(21 \%) \text { signs of } \\
\text { hypogtycemia, }(39 \%) \text { foot care, and }(77 \%) \text { diet. } 27 \% \text { of diabetic patients did not receive any } \\
\text { education. }\end{array}$ \\
\hline (Al-Khathami et al., 2010) & Access & obstetrics & $\begin{array}{l}\text { Language barriers between expiate professional special nurses and patients. Patient reported: } \\
70 \% \text { felt uncomfortable during communication, } 50 \% \text { of nurses avoid conversation, } 70 \% \text { of } \\
\text { nurses end the conversation. }\end{array}$ \\
\hline (Al-Makhaita et al., 2014) & organization culture & Job stress & $\begin{array}{l}\text { The overall stress in the professionals was } 46 \% \text {, The source of stress: work shifts }(90 \% 0 \text {, } \\
\text { non-bachelor's degree }(83 \%) \text {. }\end{array}$ \\
\hline (Almalki et al., 2012) & Effectiveness & $\begin{array}{l}\text { Quality of nurses' } \\
\text { work life }\end{array}$ & $\begin{array}{l}\text { Nurses stated: } \\
(61 \%) \text { inadequate salary, }(60 \%) \text { insecure working environment, }(70.5 \%) \text { unhappy with working } \\
\text { hours, }(58 \%) \text { unable to balance work with their family needs. }\end{array}$ \\
\hline \multirow[b]{2}{*}{ (Almoajel et al., 2014) } & \multirow[b]{2}{*}{ Access } & \multirow[b]{2}{*}{$\begin{array}{l}\text { Patients } \\
\text { satisfaction }\end{array}$} & $(86 \%)$ of patients reported distance between center and their home acceptable. \\
\hline & & & $\begin{array}{l}\text { While, some patients were not satisfied with centers services: } 37 \% \text { patient agreed working } \\
\text { hours in center is not suitable, Long waiting time (39\%), difficult to get an appointment }(37 \%) \text {, } \\
\text { not easy to access to center at any time ( } 49 \%) \text {, not contact for missing appointment }(65 \%) \text {, not } \\
\text { easy to referral procedure to hospital }(22 \%) \text {, not seeing the same doctor when they followed up } \\
(31 \%) \text {, and clinic does not listen to patients complaints }(62 \%) \text {. }\end{array}$ \\
\hline
\end{tabular}




\begin{tabular}{|c|c|c|c|}
\hline (Al-Mosilhi \& Kurashi, 2006) & $\begin{array}{l}\text { Development } \\
\text { professional }\end{array}$ & $\begin{array}{l}\text { Attitudes/ } \\
\text { obstacles }\end{array}$ & $\begin{array}{l}\text { Most physicians were aware of CME. The most obstacles for attending CME: }(37 \%) \text { lack of } \\
\text { time, }(26 \%) \text { non-availability of suitable, }(14 \%) \text { distance, }(17 \%) \text { practice commitments, subjects } \\
\text { covered }(17 \%) .2 \% \text { had PHC postgraduate qualification in primary health care. }\end{array}$ \\
\hline $\begin{array}{l}\text { (Al-Mustafa \& Abulrahi, } \\
\text { 2003) }\end{array}$ & Access & Hypertension & $\begin{array}{l}\text { PHC registers recorded the expected total number of adult hypertension patients between } 16 \% \\
\text { and } 36 \% \text { in the community. The study found that the services offered only cover less than } 20 \% \text { of } \\
\text { the expected number of adult hypertensives. }\end{array}$ \\
\hline (Alsharif \& Al-Khaldi, 2001) & $\begin{array}{l}\text { Development } \\
\text { professional }\end{array}$ & $\begin{array}{l}\text { Attitudes/ } \\
\text { obstacles }\end{array}$ & $\begin{array}{l}\text { Most physicians had a positive attitude toward CME, } 26 \% \text { had postgraduate qualifications } \\
\text { barriers to attending CME: Work overload } 928 \% 0 \text {, and lack of time ( } 43 \%) \text {. }\end{array}$ \\
\hline $\begin{array}{l}\text { (Alzaied \& Alshammari, } \\
\text { 2016) }\end{array}$ & access/ Effectives & $\begin{array}{l}\text { Evaluation/ } \\
\text { Obstacles }\end{array}$ & $\begin{array}{l}\text { PHC had a good order for accessible and effective. Obstacles for PHC: communication between } \\
\text { users and staffs, staffs need more training, incentives, and scholarship. }\end{array}$ \\
\hline (Bawakid et al., 2017) & organization culture & Job stress & $\begin{array}{l}\text { Sources of stress in physicians: } \\
\text { Evening shift }(23 \%) \text {, outside duties }(81 \%) \text {, and PHCCS administrative transaction is slow ( } 74 \%) \text {. }\end{array}$ \\
\hline (Dashash \& Mukhtar, 2003) & Effectives & Asthma & $\begin{array}{l}\text { Guidelines were not followed: } \\
\text { Use of non-recommend, over and under prescribing, drug interactions, poor follow up and } \\
\text { continuity of care, and suboptimal care for asthmatic children. }\end{array}$ \\
\hline (Diaz-Perez et al., 2004) & Access/Effectives & $\begin{array}{l}\text { Mobile medical } \\
\text { unit }\end{array}$ & $\begin{array}{l}35 \% \text { of patient who received the consultation from the mobile unit, not visited any of the clinics } \\
\text { for follow up during the following year. }\end{array}$ \\
\hline (El-Gilany \& Aref, 2000) & Access & Maternal health & $\begin{array}{l}\text { The coverage of maternal care in high in urban }(67 \%) \text { and rural }(96 \%) \text {. Low socioeconomic } \\
\text { group received less maternal care. }\end{array}$ \\
\hline (Khan et al., 2011) & organization culture & Diabetes & $\begin{array}{l}\text { Weakness of knowledge (diabetes) in physicians: } \\
\text { Unknow correct diagnostic criteria of type } 2 \text { diabetes } 928 \%) \text {, knew correct angle of insulin } \\
\text { injection ( } 35 \% 0 \text {, and not agree about diabetic self-management education }(87 \%) \text {. }\end{array}$ \\
\hline (Kishk \& Al Juhani, 2006) & Organization culture & Job satisfaction & $\begin{array}{l}\text { Characteristics in primary care: work team, corporate work environment, attitude improving } \\
\text { between staff. } \\
\text { Job dissatisfaction was: doctors }(52 \%) \text { and nurses }(67 \%) \text {, includes: Workload }(70 \%) \text {, } \\
\text { professional opportunities }(78 \%) \text {, and appreciation reward }(67 \%) \text {. }\end{array}$ \\
\hline (Tian, 2011) & $\begin{array}{l}\text { Interface with secondary } \\
\text { care }\end{array}$ & Electronic-Referral & $\begin{array}{l}\text { E-referral had successful reducing wait times and improve access to secondary, quality of } \\
\text { referral communication, and complete and accurate information of referral patients. }\end{array}$ \\
\hline (Wallace et al., 2012) & Effectives & $\begin{array}{l}\text { Electronic } \\
\text { Education }\end{array}$ & $\begin{array}{l}85 \% \text { of participants reported using mobile devices and their application, can provide easy, quick } \\
\text { accessing to journals, news, multimedia. }\end{array}$ \\
\hline
\end{tabular}




\subsection{Interface with Secondary Care}

In 1986, a referral system was established to improve communication and coordination between primary health care and hospitals (Al-Ahmadi \& Roland, 2005). Evidence indicates that the implementation of the referral system reduced hospital outpatient visits by 32\% (Albattal, 2014). However, several studies identified a lack of information on referral forms, including history (36\%), vital signs $(30 \%)$, the results of examination $(45 \%)$, the results of investigation (52\%), provisional diagnosis (50\%) and the treatment given in PHCCs (47\%; (Al-Alfi et al., 2007). In addition, feedback reports were received for only $30 \%$ of referrals to hospitals (Al-Alfi et al., 2007; Albattal, 2014). The main factors reportedly contributing to inappropriate referrals in general practice are a poor awareness of available secondary care clinics $(67 \%)$, a lack of referral feedback $(86 \%)$ and the difficulty of communicating with specialists by phone (91\%; (Albattal, 2014). Moreover, hospital feedback to PHCCs was released only at the request of patients or health centres (Albattal, 2014), and the feedback forms lacked information, including diagnosis $(15 \%)$, advice $(100 \%)$ and the results of investigations $(21 \%$; (Al-Ahmadi \& Roland, 2005). In contrast, electronic referral was related to success in improving the quality of referral communication between primary and secondary health services and providing complete and accurate information about referral patients (Tian, 2011).

\subsection{Organisational Culture}

Several studies reported many positive organisational characteristics in PHCCs, such as work teams, the corporate work environment, continuing education (Al-Mosilhi \& Kurashi, 2006) and positive staff attitudes towards improvements through the implementation of EBM (Al-Ansary \& Khoja, 2002). However, many studies also pointed out that primary care professionals' general sense of job significance was poor (Almalki et al., 2012; Kishk \& Al Juhani, 2006). These studies found that more than half of professionals were dissatisfied with management practices, incentives, workloads and medical facilities (Almalki et al., 2012; Kishk \& Al Juhani, 2006). Studies on stress among primary healthcare professionals found that sources of stress included outside duties (81\%), paperwork (81\%) and slow administrative transactions (74\%; (Bawakid et al., 2017; Khan et al., 2011).

\subsection{Professional Development Strategies}

Evidence indicates that the professional development strategies in PHCCs are inadequate (Al-Mosilhi \& Kurashi, 2006; Alsharif \& Al-Khaldi, 2001). Studies have shown that only about one-third of physicians in primary health care had postgraduate qualifications, and only $2 \%$ of these were in primary health care (Al-Mosilhi \& Kurashi, 2006; Alsharif \& Al-Khaldi, 2001). Even fewer were shown to have access to international journals (Alsharif \& Al-Khaldi, 2001). Major additional obstacles to professional development were work pressure, distance from educational institutions, the unavailability of suitable continuous medical education (CME) and a lack of time (Al-Mosilhi \& Kurashi, 2006; Alsharif \& Al-Khaldi, 2001).

\section{Discussion}

The Saudi primary healthcare programme has achieved considerable success, and it is considered a pioneering programme in the country within a few years of its establishment. This is reflected in certain effective and accessible primary healthcare services, such as diabetes care education and maternal health care. However, dental services are still unavailable in most PHCCs, and variations in some aspects of primary care quality, such as the management of chronic diseases, have been identified. In a study performed in Canada, similar variations in primary healthcare quality were observed (Lévesque et al., 2012).

Mobile medical units have been implemented as an alternative solution to supply the standard of dental care to reach the underserved population in several countries. These units have been shown to be highly successful in improving access and cost-efficiency (Diaz-Perez et al., 2004). A school-based study in the south of Africa showed that having a mobile dental unit was cost effective; it showed cost savings of $9.1 \%$ and eliminated missed appointments (Molete, Chola, \& Hofman, 2016). Similarly, a cross-sectional study comparing the costs of a fixed facility and mobile dental unit in Thailand stated that the mobile dental unit provided comprehensive oral health at a lower cost (Tianviwat, Chongsuvivatwong, \& Birch, 2009). Thus, this intervention can be implemented as alternative solution for unviable dental services in some primary healthcare settings in Saudi Arabia.

The clinical care quality is affected by failures to adhere to the appropriate referral patterns and guidelines of EBM. Attempts have been made to promote the practices of EBM in Saudi primary health care, but because of poor professional development and guideline dissemination, these efforts have yet to achieve their potential. Studies have shown that physicians face barriers to education, such as work pressure, distance, the unavailability of suitable CME and a lack of time. In addition, few physicians have access to international journals. Kredo et al. (2016) point out that increased implementation of evidence-based clinical guidelines will contribute to improving 
the quality of primary care. This review found that Saudi physicians have positive attitudes towards EBM; however, their lack of training in EBM practices prevents its implementation. This is similar to the findings that general practitioners in Australia have positive attitudes towards EMB, but in daily practice, they are not employing the terminology and performing the tasks involved in EBM implementation (Young \& Ward, 2001).

The quality of feedback reports and referral letters demonstrates that communication between primary care physicians and hospital specialists is poor. This review observed a worrying lack of basic clinical information in both referral letters and feedback reports, including the results of clinical examinations and investigations and the duration of complaints. Senitan, Alhaiti, Gillespie, Alotaibi, and Lenon (2017) report that providing hospital specialists with adequate clinical information about the health status of patients, including evaluations of their initial health conditions and all specific questions that need to be addressed, is important for saving patients' lives.

Electronic referral (e-referral) may improve the interfacing between primary and secondary healthcare providers by allowing general practitioners from primary health care to electronically request referrals to specialist health professionals (Naseriasl, Adham, \& Janati, 2015). E-referrals have been defined as the method of transferring patient care responsibility from referring healthcare providers to specialist healthcare providers and the responsibility for transferring appropriate information back in an appropriate timeframe (Tian, 2011). Several countries, including the United States, United Kingdom, Australia, New Zealand, Denmark and the Netherlands, have implemented e-referrals to improve the quality of the referral system in health care (Naseriasl et al., 2015; Tian, 2011). Consequently, these countries have noted improvements in the quality of the interface, accurate transfers, reduced wait times, more accurate feedback information and complete health information. Thus, the health referral system may be improved by implementing e-referral in Saudi Arabia.

In this review, wide variations in the quality of interpersonal care were observed. These variations are related to language barriers and cultural gaps between patients and healthcare professionals. Most of Saudi Arabia's primary healthcare professionals are non-Saudi, and they may not speak Arabic, their patients' main language. Online translation tools like MediBabble offer a possible solution for overcoming challenges related to language barriers. MediBabble presents medical professionals a fast, convenient and free interpreter. Using advanced voice recognition software, translations of medical instructions and questions are presented to obtain a standard medical history (Irfan \& Ginige, 2018; Rahman, 2017). This tool can be used both offline and online (Sheik-Ali, Dowlut, \& McConaghie, 2016), and it translates to six languages, namely, English, Russian, Cantonese, Haitian Creole, Mandarin and Spanish (Sheik-Ali et al., 2016). A case study showed that both patients and medical professionals were highly satisfied with MediBabble, reporting that the tool was easy and fast in terms of collecting and translating information (Boujon, Bouillon, Spechbach, Gerlach, \& Strasly, 2018). In brief, the MediBabble application shows success as a medical translator; therefore, it can be applied in Saudi Arabia.

Primary healthcare professionals' lack of access to information and training is a major concern, as they are unable to maintain their skills and knowledge (Hughes, 2008); Johnston, Crombie, Alder, Davies, and Millard (2000) pointed out that improving professionals' access to evidence-based guidelines and medical information is an essential requirement for improving the quality of primary health care.

Mobile devices and their applications present a possible solution for helping healthcare professionals overcome the barriers to education and the practice of EBM. These devices have become common in healthcare settings, contributing to the fast growth in the development of medical software applications in this field (Wallace et al., 2012). Mobile applications like QuantiaMD and MedPage Today are used by practicing healthcare professionals to continuously engage in medical education activities that keep them informed about recent medical practice and evidence-based information (Ventola, 2014). The QuantiaMD application provides well-scripted interactive case studies that make it possible to share with colleagues (Ozdalga, Ozdalga, \& Ahuja, 2012). In addition, MedPage Today is a popular mobile application that provides continuing medical education news services and free continuing education among healthcare professionals (Ventola, 2014). A 2011 survey of Canadian medical schools showed that $55 \%, 95 \%$ and $75 \%$ of students, residents and faculty, respectively, agreed that mobile devices provide fast access to educational resources and have positive education effects (Wallace et al., 2012). Therefore, the Saudi primary healthcare system can benefit from implementing mobile devices and their applications.

The motivation and morale of healthcare centre staff may be improved by concentrating on patient load, working hours, salaries and the improvement of facilities and resources. The employment conditions of non-Saudi professionals and their roles in improving quality must also be examined. A sense of job security should be granted through contract conditions.

This review has certain limitations. Most of the studies examined were carried out in Ministry of Health institutions, the country's major providers of primary health care, while other providers included military health 
institutions. Factors that delay the achievement of quality vary from one provider to another because each primary healthcare provider has different goals and priorities for providing quality services. The studies in this review were varied in their design method and in the aspects of care studied, limiting the option of pooling their evidence.

\section{Conclusion}

This review found that the primary healthcare agenda faces significant challenges in Saudi Arabia. These challenges include the lack of some services in PHCCs, such as dental care; issues of interfaces with hospitals, such as missing important clinical information from referral letters and feedback reports; language barriers between health professionals and patients; and primary healthcare professionals' lack of access to information and training. The challenges identified in this review can be addressed by improving all aspects of the primary healthcare system and establishing a comprehensive quality assessment system. This review suggests some potential improvements that have been implemented by other systems to address these challenges. First, mobile dental units have been implemented as an alternative successful solution for limited dental services in the healthcare system in many countries, and these units can be adopted in Saudi Arabia. Second, an effective solution for challenges in the referral system that may be applicable is an e-referral system, which has been implemented in several countries, including the United States and Australia. Such e-referral systems present complete, accurate information about referred patients. Third, the MediBabble application presents a possible solution for overcoming language barriers. Fourth, mobile applications, such as QuantiaMD and MedPage Today, provide easy and fast access to health education resources and keep health professionals informed about recent medical practice and evidence-based information. Further research on adopting solutions in Saudi Arabia that have been successfully implemented elsewhere is needed.

\section{Competing Interests Statement}

The authors declare that there are no competing or potential conflicts of interest.

\section{References}

Al-Ahmadi, H., \& Roland, M. (2005). Quality of primary health care in Saudi Arabia: a comprehensive review. International Journal for Quality in Health Care, 17(4), 331-346. https://doi.org/10.1093/intqhe/mzi046

Al-Alfi, M. A., Al-Saigul, A. M., Abed-Elbast, A. M., Sourour, A. M., \& Ramzy, H. A. (2007). Quality of primary care referral letters and feedback reports in Buraidah, Qassim region, Saudi Arabia. Journal of family \& community medicine, 14(3), 113. Retrieved from https://www.ncbi.nlm.nih.gov/pmc/articles/PMC3410153/

Al-Ansary, L. A., \& Khoja, T. A. (2002). The place of evidence-based medicine among primary health care physicians in Riyadh region, Saudi Arabia. Family practice, 19(5), 537-542. https://doi.org/10.1093/fampra/19.5.537

Al-Jaber, A., \& Da'ar, O. B. (2016). Primary health care centers, extent of challenges and demand for oral health care in Riyadh, Saudi Arabia. BMC health services research, 16(1), 628. https://doi.org/10.1186/s12913-016-1876-6

Al-Khaldi, Y. M., \& Al-Sharif, A. I. (2002). Availability of resources of diabetic care in primary health care settings in Aseer region, Saudi Arabia. Saudi Medical Journal, 23(12), 1509-1513.

Al-Khaldi, Y. M., \& Khan, M. Y. (2000). Audit of a diabetic health education program at a large Primary Health Care Center in Asir region. Saudi Medical Journal, 21(9), 838-842.

Al-Khathami, A. M., Kojan, S. W., Aljumah, M. A., Alqahtani, H., \& Alrwaili, H. (2010). The effect of nurse-patient language barrier on patients' satisfaction. Saudi medical journal, 31(12), 1355-1358.

Al-Makhaita, H. M., Sabra, A. A., \& Hafez, A. S. (2014). Predictors of work-related stress among nurses working in primary and secondary health care levels in Dammam, Eastern Saudi Arabia. Journal of family \& community medicine, 21(2), 79. https://doi.org/10.4103/2230-8229.134762

Al-Mosilhi, A. H., \& Kurashi, N. Y. (2006). Current situation of continuing medical education for primary health care physicians in Al-Madinah Al-Munawarah province, Saudi Arabia. Journal of family \& community medicine, 13(2), 75.

Al-Mustafa, B. A., \& Abulrahi, H. A. (2003). The role of primary health care centers in managing hypertension. How far are they involved? Saudi medical journal, 24(5), 460-465.

Al-Mutairi, E. (2017). Healthcare Workforce Challenges in Saudi Arabia. Retrieved from http://www.csc.org.sa/Arabic/NationalCommittees/NationalCommitteesList/Comm12/Documents/Healthcar e\%20Workforce\%20Gap\%20in\%20Saudi\%20Arabia.pdf 
Albattal, S. M. (2014). Management of inappropriate referrals in Wazarat health center, Riyadh, Saudi Arabia. https://doi.org/10.5455/ijmsph.2013.141220131

Albrecht, U.-V., Behrends, M., Schmeer, R., Matthies, H. K., \& Von Jan, U. (2013). Usage of Multilingual Mobile Translation Applications in Clinical Settings. https://doi.org/10.2196/mhealth.2866

Alfaqeeh, G., Cook, E. J., Randhawa, G., \& Ali, N. (2017). Access and utilisation of primary health care services comparing urban and rural areas of Riyadh Providence, Kingdom of Saudi Arabia. BMC health services research, 17(1), 106. https://doi.org/10.1186/s12913-017-1983-z

Alhamad, Z. (2013). Reasons for missing appointments in general clinics of primary health care center in Riyadh Military Hospital, Saudi Arabia. https://doi.org/10.5455/ijmsph.2013.2.256-265

Almalki, M. J., FitzGerald, G., \& Clark, M. (2012). Quality of work life among primary health care nurses in the Jazan region, Saudi Arabia: a cross-sectional study. Human resources for health, 10(1), 30. https://doi.org/10.1186/1478-4491-10-30

Almasabi, M. H. (2013). An overview of quality and accreditation in the health sector within Saudi Arabia.

Almoajel, A., Fetohi, E., \& Alshamrani, A. (2014). Patient satisfaction with primary health care in Jubail City, Saudi Arabia. World Journal of medical sciences, 11(2), 255-264.

Alsharif, A. I., \& Al-Khaldi, Y. M. (2001). Attitude, practice and needs for continuing medical education among primary health care doctors in Asir region. Journal of family \& community medicine, 8(3), 37.

Alzaied, T. A. M., \& Alshammari, A. (2016). An Evaluation of Primary Healthcare Centers (PHC) Services: The Views of Users. Health Science Journal, 10(2).

Bawakid, K., Ola, A., Najlaa, M., Shah, H., Ibrahim , A., Akkad, N., \& Mufti, F. (2017). Burnout of Physicians Working in Primary Health Care Centers under Ministry of Health Jeddah, Saudi Arabia. https://doi.org/10.7759/cureus. 1877

Boujon, V., Bouillon, P., Spechbach, H., Gerlach, J., \& Strasly, I. (2018). Can Speech-Enabled Phraselators Improve Healthcare Accessibility? A Case Study Comparing BabelDr with MediBabble for Anamnesis in Emergency Settings.

Dashash, N. A., \& Mukhtar, S. H. (2003). Prescribing for asthmatic children in primary care. Are we following guidelines? Saudi medical journal, 24(5), 507-511.

Diaz-Perez, M. d. J., Farley, T., \& Cabanis, C. M. (2004). Program to improve access to health care among Mexican immigrants in rural Colorado. 20, 258-264. https://doi.org/10.1111/j.1748-0361.2004.tb00037.x

Duggirala, M., Rajendran, C., \& Anantharaman, R. (2008). Patient-perceived dimensions of total quality service in healthcare. Benchmarking: An International Journal, 15(5), 560-583. https://doi.org/10.1108/14635770810903150

El-Gilany, A.-H., \& Aref, Y. (2000). Failure to register for antenatal care at local primary health care centers. Annals of Saudi medicine, 20(3/4), 229-232. https://doi.org/10.5144/0256-4947.2000.229

Hughes, R. (2008). Patient safety and quality: An evidence-based handbook for nurses (Vol. 3). Agency for Healthcare Research and Quality Rockville, MD.

Irfan, M. E., \& Ginige, J. A. (2018). Comparative Study of Medical Reference and Information Mobile Apps for Healthcare Professionals and Students. Studies in health technology and informatics, 254, 43-52.

Johnston, G., Crombie, I., Alder, E., Davies, H., \& Millard, A. (2000). Reviewing audit: barriers and facilitating factors for effective clinical audit. BMJ Quality \& Safety, 9(1), 23-36. https://doi.org/10.1136/qhc.9.1.23

Khan, N. A.-A., Lateef, N. A.-A., Khamseen, N. A.-A., Al Aithan, N. A.-A., \& Al Ibrahim, N. A.-A. (2011). Knowledge, attitude and practice of ministry of health primary health care physicians in the management of type 2 diabetes mellitus: A crosssectional study in the Al Hasa District of Saudi Arabia, 2010. Nigerian Journal of Clinical Practice, 14(1), 52-59. https://doi.org/10.4103/1119-3077.79241

Kishk, N. A., \& Al Juhani, A. M. (2006). Job satisfaction among primary health care physicians and nurses in Al-madinah Al-munawwara.

Kredo, T., Bernhardsson, S., Machingaidze, S., Young, T., Louw, Q., Ochodo, E., \& Grimmer, K. (2016). Guide to clinical practice guidelines: the current state of play. International Journal for Quality in Health Care, 28(1), 122-128. https://doi.org/10.1093/intqhe/mzv115 
Lévesque, J.-F., Feldman, D. E., Lemieux, V., Tourigny, A., Lavoie, J.-P., \& Tousignant, P. (2012). Variations in patients' assessment of chronic illness care across organizational models of primary health care: a multilevel cohort analysis. Healthcare Policy, 8(2), e108. https://doi.org/10.12927/hcpol.2012.23105

Littlewood, J., \& Yousuf, S. (2000). Primary health care in Saudi Arabia: applying global aspects of health for all, locally. Journal of Advanced Nursing, 32(3), 675-681. https://doi.org/10.1046/j.1365-2648.2000.01527.x

Ministry of Health- Saudi Arabia. (2013). Health Statistics Annual Book. Retrieved from https://www.moh.gov.sa/en/Ministry/Statistics/book/Documents/Statistics-Book-1434.pdf

Molete, M., Chola, L., \& Hofman, K. (2016). Costs of a school-based dental mobile service in South Africa. BMC Health Services Research, 16(1). https://doi.org/10.1186/s12913-016-1827-2

Naseriasl, M., Adham, D., \& Janati, A. (2015). E-referral solutions: successful experiences, key features and $\begin{array}{llllll}\text { challenges-a systematic } & \text { review. } & \text { Materia } & \text { socio-medica, } & 27(3), & \end{array}$ https://doi.org/10.5455/msm.2015.27.195-199

Ozdalga, E., Ozdalga, A., \& Ahuja, N. (2012). The smartphone in medicine: a review of current and potential use among physicians and students. Journal of medical Internet research, 14(5). https://doi.org/10.2196/jmir.1994

Rahman, A. A. (2017). Rising up to the challenge: Strategies to improve health care delivery for resettled Syrian refugees in Canada. University of Toronto Medical Journal, 94(1), 42.

Raposo, M. L., Alves, H. M., \& Duarte, P. A. (2009). Dimensions of service quality and satisfaction in healthcare: a patient's satisfaction index. Service Business, 3(1), 85-100. https://doi.org/10.1007/s11628-008-0055-1

Schuster, M. A., McGlynn, E. A., \& Brook, R. H. (2005). How Good Is the Quality of Health Care in the United States? https://doi.org/10.1111/j.1468-0009.2005.00403.x

Senitan, M., Alhaiti, A. H., Gillespie, J., Alotaibi, B. F., \& Lenon, G. B. (2017). The Referral System between Primary and Secondary Health Care in Saudi Arabia for Patients with Type 2 Diabetes: A Systematic Review. Journal of diabetes research, 2017. https://doi.org/10.1155/2017/4183604

Sheik-Ali, S., Dowlut, N., \& McConaghie, G. (2016). Breaking down language barriers with technology. The Bulletin of the Royal College of Surgeons of England, 98(3), 138-140. https://doi.org/10.1308/rcsbull.2016.138

Tian, L. (2011). Improving knowledge management between primary and secondary healthcare: an e-referral project. Health Care Inform Rev Online, 15, 31-37.

Tianviwat, S., Chongsuvivatwong, V., \& Birch, S. (2009). Estimating Unit Costs for Dental Service Delivery in Institutional and Community-Based Settings in Southern Thailand. Asia-Pacific Journal of Public Health, 21(1), 84-93. https://doi.org/10.1177/1010539508327246

Ventola, C. L. (2014). Mobile devices and apps for health care professionals: uses and benefits. Pharmacy and Therapeutics, 39(5), 356.

Wallace, S., Clark, M., \& White, J. (2012). 'It's on my iPhone': attitudes to the use of mobile computing devices in medical education, a mixed-methods study. BMJ open, 2(4), e001099. https://doi.org/10.1136/bmjopen-2012-001099

World Health Organization [WHO]. (2006). Quality of Care: A process for making strategic choices in health systems. Retrieved from http://www.who.int/management/quality/assurance/QualityCare_B.Def.pdf

World Health Organization [WHO]. (2008). The world health report 2008: primary health care now more than ever. Retrieved from http://www.who.int/whr/2008/whr08_en.pdf

Young, J. M., \& Ward, J. E. (2001). Evidence-based medicine in general practice: beliefs and barriers among Australian GPs. Journal of evaluation in clinical practice, $7(2)$, 201-210. https://doi.org/10.1046/j.1365-2753.2001.00294.x

\section{Copyrights}

Copyright for this article is retained by the author(s), with first publication rights granted to the journal.

This is an open-access article distributed under the terms and conditions of the Creative Commons Attribution license (http://creativecommons.org/licenses/by/4.0/). 